\title{
ACTIVE LEARNING IN AN ELECTRONIC DESIGN AUTOMATION COURSE
}

\author{
Diane T. Rover, Nayda G. Santiago, and Mel M. Tsai \\ Department of Electrical and Computer Engineering \\ Michigan State University \\ East Lansing, MI 48824-1226 \\ rover@egr.msu.edu
}

\begin{abstract}
This paper summarizes the rationale behind revision of an electronic design automation course and the resulting learning objectives and course model. Early experiences are highlighted.
\end{abstract}

\section{INTRODUCTION}

One of the key microelectronic system design courses in the electrical and computer engineering programs at Michigan State University underwent course review and development in the context of several confluent efforts. These efforts included restructuring of the undergraduate program in computer engineering by an interdepartmental task force starting in 1996 [1], upgrading of the system-design laboratory with substantial university support in 1997, enhancing senior-level design courses with research concepts as part of an NSF Combined ResearchCurriculum Development project beginning in 1997 [2], and preparing for first-time ABET accreditation under Engineering Criteria 2000 during 1998. The course is ECE 411, Electronic Design Automation [3]. Certain objectives of the convergent efforts, as well as experiences of the faculty in research and education, guided the course development.

Early on, the task force identified objectives for the computer engineering program, including the following:

- to provide students with fundamental knowledge in computer hardware and software codesign so that they can adapt to rapidly changing computer technology;

- to familiarize students with state-of-the-art technologies so that they can possess the necessary skills to contribute to the computer industry;

- to teach fundamentals, using specific technologies as examples; and

- $\quad$ to provide hands-on experience.

Subsequently, the faculty completed a self-assessment of the program, including benchmarking and employer feedback, to identify strengths and weaknesses as a basis for the laboratory upgrade and accreditation process. The following aims were noted as strategic is realizing program goals:

- formal integration of hardware-software issues, especially in the context of embedded systems;

- use of contemporary engineering design tools; and

- $\quad$ use of high-level languages and environments in upper level computer engineering courses.

Additionally, the objectives of the NSF project (called VESL, Visions for Embedded Systems Laboratories) reinforced these plans and targeted the following research topics for transfer into the instructional domain, in particular, into the electronic design automation course: testing of hardware/software systems, codesign, software prototyping, and debugging. Finally, attention turned to the role of the course in the educational programs and the course itself. ECE 411 is a major elective in both the electrical engineering and computer engineering programs. In the computer engineering program, it is in a so-called hardware emphasis group of courses, which is intended to provide depth in the curriculum. Other emphasis groups are software and communications.

In the remaining sections of this paper, ECE 411 is focused on, including its learning objectives, course model, and early experiences with the revised course (first offered in Fall 1998).

\section{COURSE LEARNING OBJECTIVES}

To meet the program objectives and facilitate the accreditation and course-quality improvement processes, the faculty developed a set of course learning objectives for ECE 411.

Students in the course will learn about the design and prototyping of digital circuits and systems using contemporary high-level methods and tools. At the completion of this course, each student will have actively participated as a member of a design-project team. Each team will synthesize a digital component in programmable logic. This component will be specified, designed, prototyped, verified, and documented in such a way that it could be tested and used by other circuit and system designers.

At the completion of the course, each student will have demonstrated proficiency in:

1. Understanding and utilizing the concepts of digital circuit and system modeling and rapid prototyping;

2. Understanding the hierarchical levels of digital design;

3. Using computer-aided design tools for schematic editing, schematic capture, simulation, and timing analysis;

4. Using a contemporary hardware description language for behavioral and structural modeling of digital circuits and systems;

5. Designing digital circuits utilizing a programmable logic device from the initial point of design modeling (behavioral and/or structural) through prototyping and verification;

6. Producing comprehensive design documentation sufficient for reuse of the design as intellectual property; and

7. Participating as a member of a team-oriented design project.

The topics covered in the the course include: 
1. Electronic design hierarchy and the role of methodology

2. Digital design algorithms

3. Physical design algorithms

4. Design tools

5. Hardware description languages

6. Structural and behavioral modeling

7. Programmable logic devices

8. Rapid prototyping

9. Design synthesis

10. Design documentation

The textbook selected for the course is Digital Systems Design Using VHDL by Charles Roth. The laboratory for the course provides access to software and hardware offered through university programs of several EDA vendors, including Aldec and Xilinx. VHDL simulation is supported by the Aldec ActiveVHDL tool; VHDL synthesis, by Xilinx Foundation Express (i.e., Synopsys FPGA Express); and FPGA/CPLD mapping, by Xilinx Foundation. For prototyping, we use boards from XESS, the XS40 (Xilinx XC4010XL FPGA) and the XS95 (Xilinx XC95108 CPLD). The laboratory includes Intel Pentium-based workstations running Microsoft Windows NT. A tutorial by Roth was attended to learn about his experiences with these resources [4]. The rapid prototyping course methodology is consistent with the approach that is being taken by a number of leading universities (e.g., [5]). The week-by-week plan for the first offering of the revised course are listed on the Web [3].

\section{COURSE LEARNING MODEL}

Active learning strategies are at the heart of the course model: hands-on laboratory experiences; readily-available assistance via the Web and email (e.g., web-based tutorials, frequently-askedquestions, online documentation, instructor-student and studentstudent electronic interaction, etc.); cooperative learning [6]; and student self-assessment [7]. Thus, active learning involves both student involvement in their engineering education experience as well as student reflection and self-assessment about their learning.

As described by Smith and Waller, cooperative learning focuses on the use of small instructional groups so that students work together to maximize their own and each others' learning [6]. In ECE 411, base groups were formed early in the semester to support formal cooperative learning. Members of these groups promote each other's success and assist each other in learning; and hold themselves and others accountable for high-quality work. Groups are formed for a clearly stated purpose with well understood tasks and time schedules; and evaluate themselves and how effectively members are working together.

Student self-assessment instruments, including a journal and/or workbook, self-assessment report, student management team, the Web, and surveys, provide documentation to evaluate student preparation and achievement as well as to improve the course and program [7]. In ECE 411, survey questions, journal entries, and brief class discussions highlighted and reviewed the learning objectives. Student response has been favorable; students benefit from understanding the goals and how the assignments and other course work are a means to an end. Readers are encouraged to review the course Web site for more detailed information about the course [3].

\section{EXPERIENCES}

Student feedback indicated that the web-based quickstart guides coupled with a well-qualified teaching assistant in the lab (for advanced guidance when needed) were keys to effective laboratory experiences. In addition, students cited the course Web site as fundamental to the course. In general, students appreciated the active learning atmosphere of the classroom. During one inclass activity involving the design of a finite state machine, a student commented, "this is how we really learn (the material)." One of the most effective cooperative learning activities in ECE 411 was the base group case study (http://www.egr.msu.edu/ classes/ee411/F98/casestudy.html). Students reported that it was the most useful learning mechanism in the course. It integrated examples from the textbook. More importantly, via phases during the semester, the group brought itself along the learning curve so that every student gained some minimum proficiency with concepts and tools. Some gained more through individual effort or through teaching others in the group. Group experiences with VHDL synthesis of the case studies were brought back into the classroom instead of using lectures only. Student workbooks, similar to a portfolio, documented student progress. In their journals, students recommended ways to improve homework assignments, including more elementary programming problems and more frequent submission deadlines.

\section{ACKNOWLEDGMENTS}

We gratefully acknowledge the following companies for their support of the laboratory: Xilinx, Aldec, and XESS. This work was supported in part by NSF CAREER grant no. ACI-9624149 and NSF CRCD grant no. CDA-9700732.

\section{REFERENCES}

[1] Computer Engineering Program, Michigan State University, http://www.egr.msu.edu/cpe/.

[2] Cheng, B., Rover, D. and Mutka, M., "A Multi-Pronged Approach to Bringing Embedded Systems into Undergraduate Education," Proc. of the 1998 ASEE Annual Conf., June 1998. See also http:// www.egr.msu.edu/VESL/.

[3] EE 411 Course Web Site, Michigan State University, http://www.egr.msu.edu/classes/ee411/F98.

[4] Roth, C. H., "Teaching Digital Systems Design Using VHDL," Tutorial presented at 1998 ASEE Annual Conference, June 28, 1998.

[5] Hamblen, J.O. et al., "An Undergraduate Computer Engineering Rapid Systems Prototyping Design Laboratory," IEEE Trans. on Education, 42(1), February 1999, pp. 8-14.

[6] Smith, K.A. and Waller, A.A., "Cooperative Learning for New College Teachers," New Paradigms for College Teaching, ed. by Campbell, Wm.E. and Smith K.A., pp. 185209, Interaction Book Company, Edina, Minnesota, 1997.

[7] Rover, D.T. and Fisher, P.D., "Student Self-Assessment in Upper Level Engineering Courses," Proceedings of 1998 Frontiers in Education Conference," November 1998. 